\title{
A methodology for the formulation of water retention models in deformable soils
}

\author{
Domenico Gallipoli ${ }^{1}$ (D) $\cdot$ Agostino Walter Bruno ${ }^{2}$
}

Received: 11 February 2021 / Accepted: 8 June 2021 / Published online: 25 June 2021

(c) The Author(s) 2021

\begin{abstract}
This paper presents a novel approach to soil-water retention modelling that is based on the analysis of the material pore network. The approach postulates the existence of a differential coupling function, which relates the variation of water ratio to the variation of void ratio at constant suction. Distinct differential coupling functions have been considered, and the most general option has been integrated in a closed-form relationship between water ratio and void ratio with a suctiondependent integration constant, whose expression describes the isochoric retention behaviour. Four alternative expressions of the suction-dependent integration constant have been proposed resulting in four different, but equivalent, models linking degree of saturation, void ratio and suction. Each model predicts the variation of degree of saturation by means of four parameters, namely two parameters accounting for the effect of void ratio and two parameters accounting for the effect of suction. The models have been calibrated against laboratory data from soils with distinct particle size distributions and have shown accurate predictions of degree of saturation at different levels of suction and void ratio. Validation against additional data has also indicated that the models can extrapolate the soil behaviour to stress paths and suction levels beyond those considered during calibration.
\end{abstract}

Keywords Constitutive relations · Fabric/structure of soils · Groundwater · Partial saturation - Soil-water retention · Suction

List of symbols

a 1st parameter accounting for the effect of void ratio on retention behaviour

$b \quad 2$ nd parameter accounting for the effect of void ratio on retention behaviour

c 1st parameter accounting for the effect of suction on retention behaviour

$C(s) \quad$ Suction-dependent constant of integration

$d \quad 2$ nd parameter accounting for the effect of suction on retention behaviour

e Void ratio

$e_{w} \quad$ Water ratio

Domenico Gallipoli

domenico.gallipoli@unige.it

Agostino Walter Bruno

agostino.bruno@newcastle.ac.uk

1 Dipartimento di Ingegneria Civile, Chimica e Ambientale, Università degli Studi di Genova, Via Montallegro, 1, 16145 Genoa, Italy

2 School of Engineering, Newcastle University, Newcastle upon Tyne, UK $e_{o} \quad$ Constant void ratio

$e_{1} \quad$ Constant void ratio

$f_{c}\left(S_{r}\right) \quad$ Coupling function

$k \quad$ Isochoric retention mapping factor

$s \quad$ Suction

$S_{r} \quad$ Degree of saturation

$u_{a} \quad$ Pore air pressure

$u_{w} \quad$ Pore water pressure

\section{Introduction}

Modelling water retention in soils is important for a variety of applications from the serviceability and safety of earth structures (e.g. embankments, earth dams, cuttings, building foundations and retaining walls) to the study of landslides and the design of automated irrigation systems. Early retention models postulated a simple unique relationship between degree of saturation (or volumetric water content) and capillary suction $[4,12,46]$. Subsequent studies have, however, highlighted that water retention is also markedly 
influenced by the characteristics of the pore network [3, 13, 19, 21, 22, 30, 37]. For example, soils compacted dry of optimum exhibit two distinct pore classes, namely a class of smaller intra-aggregate pores and a class of larger inter-aggregate pores, whose size and volume evolve with stress history.

These discoveries have led to the formulation of a second category of constitutive laws, which introduce a further dependency of degree of saturation on void ratio $[18,24,29,31,43,47,50]$ and/or pore size distribution [7-11, 20, 23, 25, 27, 28, 35, 36, 40, 48]. The present paper describes a novel approach to soil-water retention modelling that falls within this second category of constitutive laws.

The proposed approach separates the influence of porosity on water retention from that of suction by considering the microstructure of the soil, which is idealised as a granular medium incorporating voids of different sizes. Some voids are empty, i.e. filled by air at pressure $u_{a}$, while other voids are saturated, i.e. filled by water at pressure $u_{w}$, which yields a suction $s=u_{a}-u_{w}$. A representation of this idealised soil is shown in Fig. 1 [49] where two types of pore water are identified, i.e. meniscus water and bulk water. Meniscus water occupies small toroidal volumes around inter-particle contacts inside the empty pores, while bulk water fills the entire pore volume. These two types of water have very different effects on soil deformation, which makes this distinction important for the formulation of mechanical models [17]. In the proposed retention

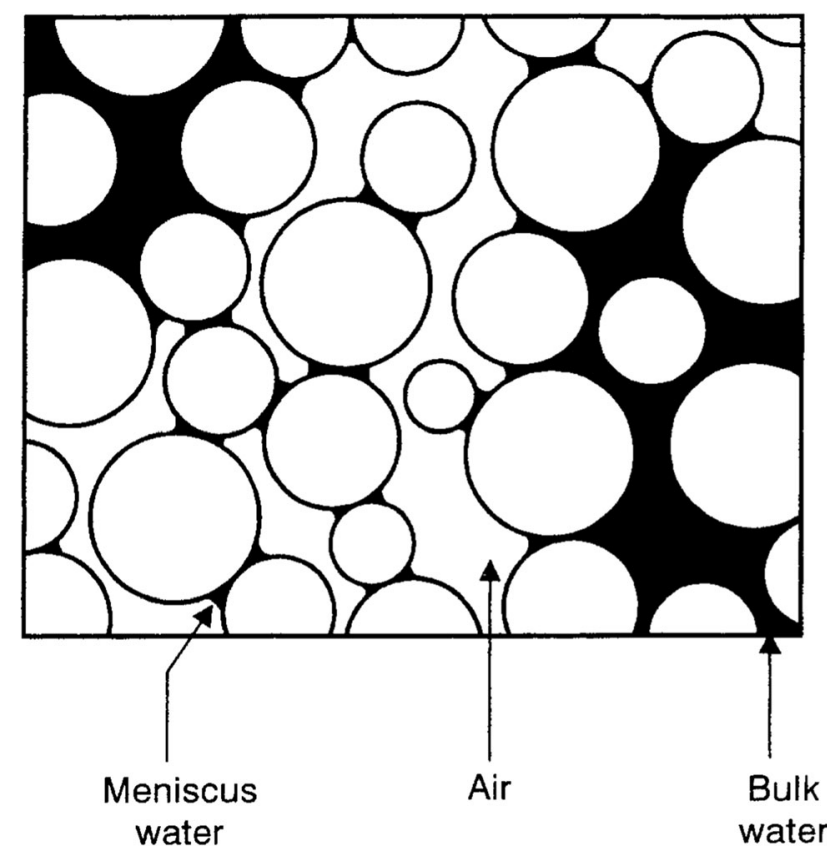

Fig. 1 Idealised unsaturated granular medium including: a pores filled by air with small meniscus water lenses at inter-particle contacts and b pores filled by water in bulk form [49] model, we assume that the volume of meniscus water is negligible and that all water exists in bulk form, which considerably simplifies the analytical derivations.

According to the law of capillarity, a pore may be either empty or saturated by water depending on the size of the pore and the level of suction. During a drying path (i.e. increasing suction), the level of suction at which air breaks into a saturated pore, thus causing it to empty, is larger if the pore is smaller. Similarly, during a wetting path (i.e. decreasing suction), the level of suction at which water floods an empty pore, thus causing it to saturate, is smaller if the pore is larger. This means that the void size separating the class of larger empty pores from the class of smaller saturated pores decreases as suction increases and, therefore, saturation reduces.

Based on the above idealisation, the proposed methodology formulates two independent constitutive laws accounting for the effects of the changes of void ratio and suction, respectively, on the retention behaviour, which are then merged into a single modelling framework. This approach can lead to the definition of different, but equivalent, retention models depending on the specific mathematical forms of these two constitutive laws. In this work, four different models with distinct mathematical forms, but similar predictive capabilities, have been defined, calibrated and validated against multiple sets of laboratory data covering soils of variable coarseness compacted at different densities [33, 34, 39, 41]. These models have also been extrapolated to stress paths and suction levels not considered during calibration, generally showing a good match to experimental data.

The proposed modelling methodology has, therefore, the advantage of increasing flexibility while associating distinct parameters to specific aspects of material behaviour, which facilitates calibration. Finally, the methodology can also be extended to account for hydraulic hysteresis [16] and to incorporate a mechanical law for predicting void ratio [5].

\section{Differential form of coupling function at constant suction}

At the core of the proposed approach, there is a differential law linking the change of water ratio, $e_{w}$ (i.e. the water volume per unit solid volume) to the change of void ratio, $e$ (i.e. the pore volume per unit solid volume) at constant suction. This law is based on the simplifying assumption that the volume of water menisci, located at inter-particle contacts inside the larger empty voids, is negligible and all water exists in bulk form inside the smaller saturated voids. Consistent with this assumption, an infinitesimal change of void ratio de at constant suction induces a corresponding 
change of water ratio $d e_{w}$, whose magnitude depends on the deformation of the pores filled, or susceptible to be filled, by water.

The problem can be analysed in a quantitative way by assuming that the induced change of water ratio $d e_{w}$ is proportional to the change of void ratio $d e$ according to a factor of proportionality $f_{c}\left(S_{r}\right)$ that is a function of the degree of saturation $S_{r}$ :

$d e_{w}=f_{c}\left(S_{r}\right) d e$

or alternatively:

$d e_{w} / d e=f_{c}\left(S_{r}\right)$

Given the relationship between state variables:

$e_{w}=S_{r} e \Rightarrow d e_{w}=S_{r} d e+e d S_{r}$

Equations $(1,2)$ can be alternatively cast as:

$d S_{r}=g_{c}\left(S_{r}\right) d e / e$

where $g_{c}\left(S_{r}\right)=f_{c}\left(S_{r}\right)-S_{r}$. Equation (4) provides an alternative physical interpretation of Eqs. $(1,2)$ as it indicates that, at each saturation level, a given percentage change of void ratio at constant suction will always produce the same change of degree of saturation regardless of the current value of void ratio.

Equations (1, 2) must also satisfy distinct physical conditions at the two saturation limits where the soil is completely dry (i.e. $S_{r}=0$ ) and fully saturated (i.e. $S_{r}=1$ ), respectively. When $S_{r}=0$, no water is present in the soil and a change of void ratio cannot produce any variation of water ratio, which means that $f_{c}(0)=0$. Conversely, when $S_{r}=1$, all pores are saturated and a change of void ratio must produce an identical change of water ratio, which means $f_{c}(1)=1$. Between these two limits, the soil is partly saturated (i.e. $0<S_{r}<1$ ) and a change of void ratio de induces a proportional change of water ratio $d e_{w}$ according to Eqs. $(1,2)$. The proportionality factor $f_{c}\left(S_{r}\right)$ is here named "coupling function" and is assumed to be not directly dependent on the chosen suction level. The coupling function can, in principle, attain both positive and negative values depending on the current saturation level, as discussed later.

Two hypotheses are here made to illustrate the possible mathematical forms of the coupling function $f_{c}\left(S_{r}\right)$. The first hypothesis assumes that volumetric deformations at constant suction produce compression or swelling of soil pores but do not alter the saturation state of each pore, i.e. empty pores remain empty, while saturated pores remain saturated. This means that a change of suction is strictly necessary to produce the flooding or drainage of individual pores. The second hypothesis assumes instead that as the soil deforms at constant suction, each pore can vary its saturation state, i.e. pores that are initially empty may become saturated and vice versa. This means that a simple variation of void sizes can produce flooding or drainage of individual pores, even if suction remains constant.

Hypothesis 1 No change in saturation state of individual pores during deformation at constant suction.

It is assumed that volumetric deformation at constant suction produces neither flooding of empty voids nor drainage of saturated voids. In this case, a change of water ratio can only occur through the compression or swelling of saturated pores. Based on this hypothesis, it is possible to postulate different pore deformation mechanisms, which imply different modes of pore water variation. For illustrative purposes, we consider here three of these possible mechanisms, which correspond to three different modes of pore water variation.

The first mechanism assumes that volumetric deformations at constant suction change the size of the larger empty pores while leaving the smaller saturated pores unaffected. No variation of water ratio therefore occurs if empty pores exist in the soil, which means that the derivative $d e_{w} / d e$ is equal to zero provided that the material is partly saturated. However, as soon as the soil becomes saturated, the void ratio coincides with the water ratio and the derivative $d e_{w} / d e$ becomes equal to one, which results in the following discontinuous form of coupling function $f_{c}\left(S_{r}\right)$ (Fig. 2):

$$
\begin{array}{ll}
f_{c}\left(S_{r}\right)=0 & \text { if } \quad 0 \leq S_{r}<1 \\
f_{c}\left(S_{r}\right)=1 & \text { if } \quad S_{r}=1
\end{array}
$$

The coupling function of Eq. (5) predicts that the water ratio of an unsaturated soil does not change during volumetric deformation at constant suction, which means that the degree of saturation $S_{r}=e_{w} / e$ is inversely proportional to void ratio, so that it will increase during compression and decrease during swelling. Note that Eq. (5) fulfils the two physical requirements of $f_{c}(0)=0$ and $f_{c}(1)=1$ for a completely dry and fully saturated soil, respectively.

The second mechanism assumes instead that volumetric deformations at constant suction produce proportionally identical changes of volume in all pores, regardless of their size and whether they are empty or saturated. This means that the changes of water ratio and void ratio are proportionally identical, i.e. $d e_{w} / e_{w}=d e / e \Rightarrow d e_{w} / d e=$ $e_{w} / e=S_{r}$, so that the coupling function coincides with the degree of saturation:

$f_{c}\left(S_{r}\right)=S_{r}$

Figure 2 shows the graph of Eq. (6) and confirms that the two physical requirements of $f_{c}(0)=0$, for a completely dry soil, and $f_{c}(1)=1$, for a fully saturated soil, are fulfilled. Note also that the coupling function of Eq. (6) 


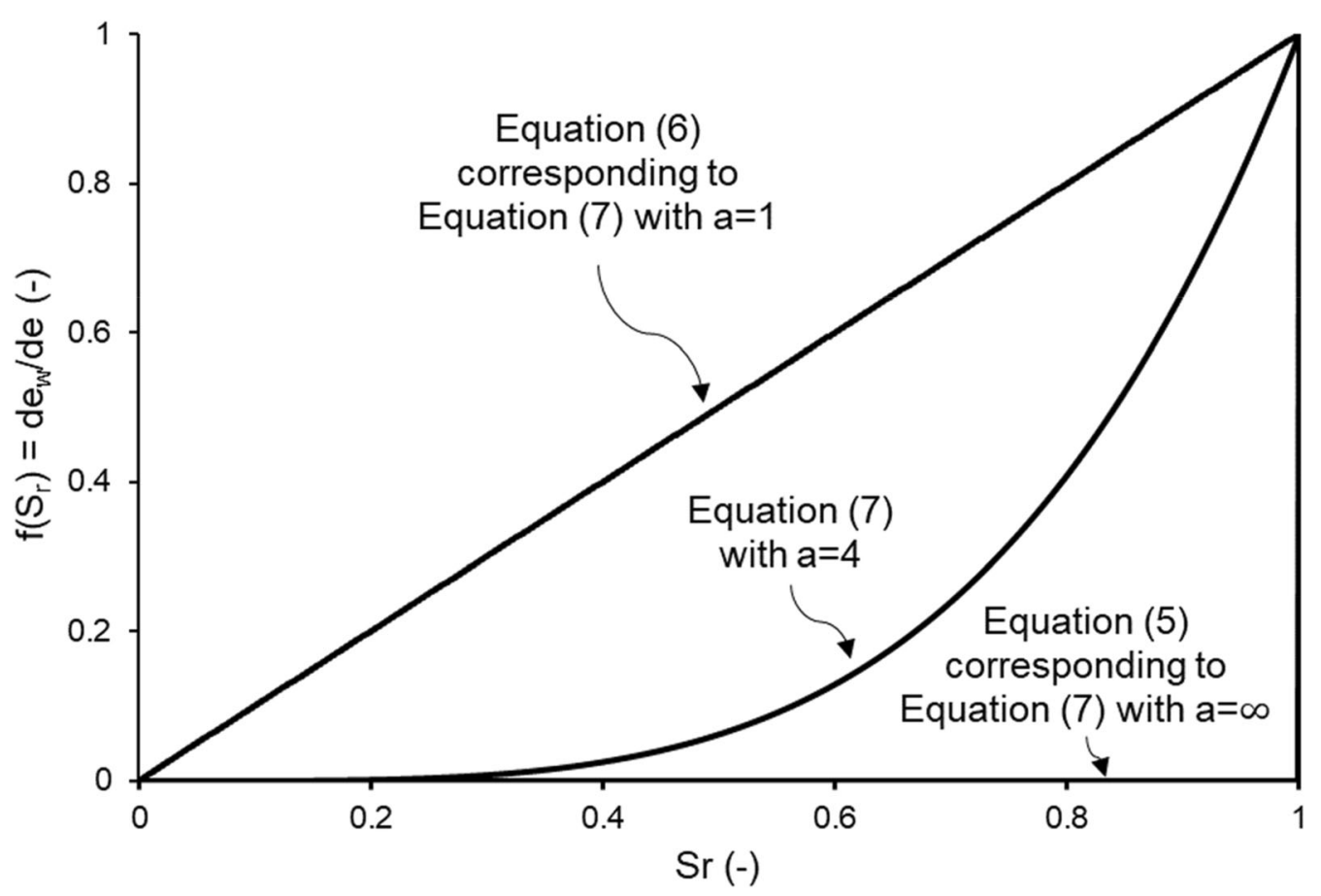

Fig. 2 Possible forms of coupling function assuming no changes of saturation state of individual pores during volumetric deformation at constant suction

implies that no change of degree of saturation is predicted during volumetric deformation at constant suction.

The two coupling functions of Eqs. (5) and (6) are useful for illustrative purposes but are not credible over the entire saturation range. This is because, at low saturation levels, water withdraws in the smallest pores that are unaffected by deformation, while the largest deformable pores are filled by air. In this condition, a change of void ratio produces negligible variations of water ratio and the coupling function tends towards Eq. (5). Instead, at high saturation levels, a change of void ratio also affects some of the saturated voids, thus producing a variation of water ratio and causing the coupling function to move from Eq. (5) towards Eq. (6). A form of coupling function consistent with this behaviour is:

$f_{c}\left(S_{r}\right)=S_{r}{ }^{a}$

where $a$ is a model parameter (Fig. 2). Equation (7) requires $0<a$ to fulfil the physical requirements of $f_{c}(0)=0$, for a completely dry soil, and $f_{c}(1)=1$, for a fully saturated soil. An even stricter condition of $1 \leq a$ must be imposed to avoid that the coupling function is bigger than the degree of saturation, which would lead to the improbable conclusion that the volumetric deformation of the smaller saturated pores is proportionally bigger than that of the larger empty pores.

Note that, as shown in Fig. 2, Eq. (7) reduces to Eq. (5) when parameter $a$ tends to infinity, while it reduces to
Eq. (6) when parameter $a$ is equal to one, which means that Eqs. (5) and (6) are particular cases of Eq. (7).

Hypothesis 2 Change in saturation state of individual pores during deformation at constant suction.

Albeit useful to understand soil behaviour, hypothesis 1 is not realistic because volumetric deformations can produce flooding of empty pores or drainage of saturated pores, even if suction remains constant.

Consider an unsaturated soil element at a given suction where all voids equal or smaller than a given size are saturated, while all voids larger than that size are empty. The size of the biggest saturated pore is inversely related to soil suction and may be calculated using a suitable capillarity law such as, for example, the law of Young-Laplace. If the soil is compressed at constant suction, the larger empty pores reduce in size and the smallest of them may attain the same dimension of the biggest saturated pores. At this point, these initially empty pores will start to suck water in under the action of capillarity and will become saturated. This means that the pore state will change from empty to saturated during compression at constant suction. A similar consideration applies to the case where the soil is subjected to swelling at constant suction as some of the initially saturated pores may become large enough to drain water out. This mechanism of pore flooding/drainage generates a change of water ratio of opposite sign with respect to the change of void ratio that has produced it. 
Therefore, if the flooding/drainage of individual pores dominates, the water ratio will increase as void ratio reduces and will reduce as void ratio increases, at constant suction. This theoretical behaviour has been experimentally observed by Buenfil et al. [6] during the isotropic compression of clayey silt samples at low suction levels. Sivakumar [41] also recorded a small water inlet into kaolin clay samples during compression at constant suction.

The mathematical form of the coupling function must, therefore, be flexible enough to attain both positive and negative values depending on degree of saturation. One expression complying with this condition is:

$f_{c}\left(S_{r}\right)=b S_{r}{ }^{a}+(1-b) S_{r}$

where $a$ and $b$ are model parameters. Equation (8) reduces to Eq. (7) when $b=1$, which means that Eq. (8) encompasses Eq. (7) and, therefore, provides a broader form of coupling, i.e. based on more general assumptions, compared to the previous case. Equation (8) also reduces to Eq. (6) when either $b=0$ (regardless of the value of $a$ ) or $a=1$ (regardless of the value of $b$ ).

To ensure that the coupling function is equal or smaller than the degree of saturation, it is necessary to impose that $0 \leq b$ and $1 \leq a$ (see Appendix for a proof). This is to avoid the unrealistic prediction of proportionally bigger deformations of the smaller flooded pores compared to the larger empty pores. Equation (8) also fulfils both requirements of $f_{c}(0)=0$, for a completely dry soil, and $f_{c}(1)=1$, for a fully saturated soil. The sensitivity of the coupling function to parameters $a$ and $b$ is demonstrated in Fig. 3, while the effect of these parameters on the attainment of negative values of the coupling function is discussed in Appendix.

\section{Integral of coupling function at constant suction}

The coupling function of Eq. (8) is substituted into Eq. (2), which is then rewritten as:

$d e_{w} / d e=b\left(e_{w} / e\right)^{a}+(1-b) e_{w} / e$

Equation (9) can be integrated in a closed form to give the following relationship between water ratio and void ratio at constant suction

$e_{w}(e, s)=\left[e^{(a-1)} /\left(1+C(s) e^{b(a-1)}\right)\right]^{1 /(a-1)}$

where $C(s)$ is the constant of integration that depends on the chosen constant suction.

By dividing both left- and right-hand sides of Eq. (10) by the void ratio, the above relationship is rewritten in terms of degree of saturation instead of water ratio as:
$S_{r}(e, s)=\left[1 /\left(1+C(s) e^{b(a-1)}\right)\right]^{1 /(a-1)}$

The expression of $C(s)$ must satisfy the two conditions of $C(0)=0$ when $s=0$ and $C(\infty) \rightarrow \infty$ when $s \rightarrow \infty$ in order to predict the correct soil saturation state at the two extremes of the suction range, i.e. $S_{r}=1$ when $s=0$ and $S_{r} \rightarrow 0$ when $s \rightarrow \infty$. Both these conditions are satisfied by the following four alternative expressions of $C(s)$ :

Option 1: $\quad C(s)=c s^{d}$

Option 2: $\quad C(s)=\log \left(1+c s^{d}\right)$

Option 3: $\quad C(s)=\log (1+c s)^{d}$

Option 4: $\quad C(s)=\exp \left(c s^{d}\right)-1$

where $c$ and $d$ are two additional model parameters (both positive). Each of the four options listed in Eqs. (12, 13, $14,15)$ leads to a workable retention model once substituted in Eq. (11). Interestingly, Eq. (12) leads to the same model proposed by Gallipoli et al. [18], which extends the van Genuchten [46] retention law to account for the effect of volumetric deformation on degree of saturation. These retention models could also be extended to incorporate hydraulic hysteresis by selecting distinct sets of parameter values inside the expression of $C(s)$, i.e. $c_{w}$ and $d_{w}$ for wetting paths and $c_{d}$ and $d_{d}$ for drying paths, respectively. The study of hydraulic hysteresis is, however, outside the scope of the present paper and has been investigated in other works [2, 14, 16, 26, 29, 38, 42, 44, 45].

Note that the four expressions of $C(s)$ listed in Eq. (12, $13,14,15)$ are only some of the possible choices and additional options may, of course, exist.

\section{Model calibration}

The expressions of $C(s)$ listed in Eq. $(12,13,14,15)$ were substituted into Eq. (11) leading to four distinct retention models in terms of parameters $a, b, c$ and $d$. These parameter values were calibrated, for each model, against different series of laboratory tests by Sivakumar [41], Raveendiraraj [34], Sharma [39] and Rampino et al. [33], respectively. Sivakumar [41] and Raveendiraraj [34] tested Speswhite kaolin samples statically compacted to $400 \mathrm{kPa}$ at a water content of $25 \%$, resulting in a dry density of about $1200 \mathrm{~kg} / \mathrm{m}^{3}$. Sharma [39] tested samples made of $90 \%$ Speswhite kaolin and $10 \%$ sodium bentonite compacted in the same way as Sivakumar [41] and Raveendiraraj [34], resulting in a marginally lower dry density of $1190 \mathrm{~kg} / \mathrm{m}^{3}$. Finally, Rampino et al. [33] tested silty sand samples that were compacted according to the modified Proctor method [1] at the optimum water content of $9.8 \%$, 

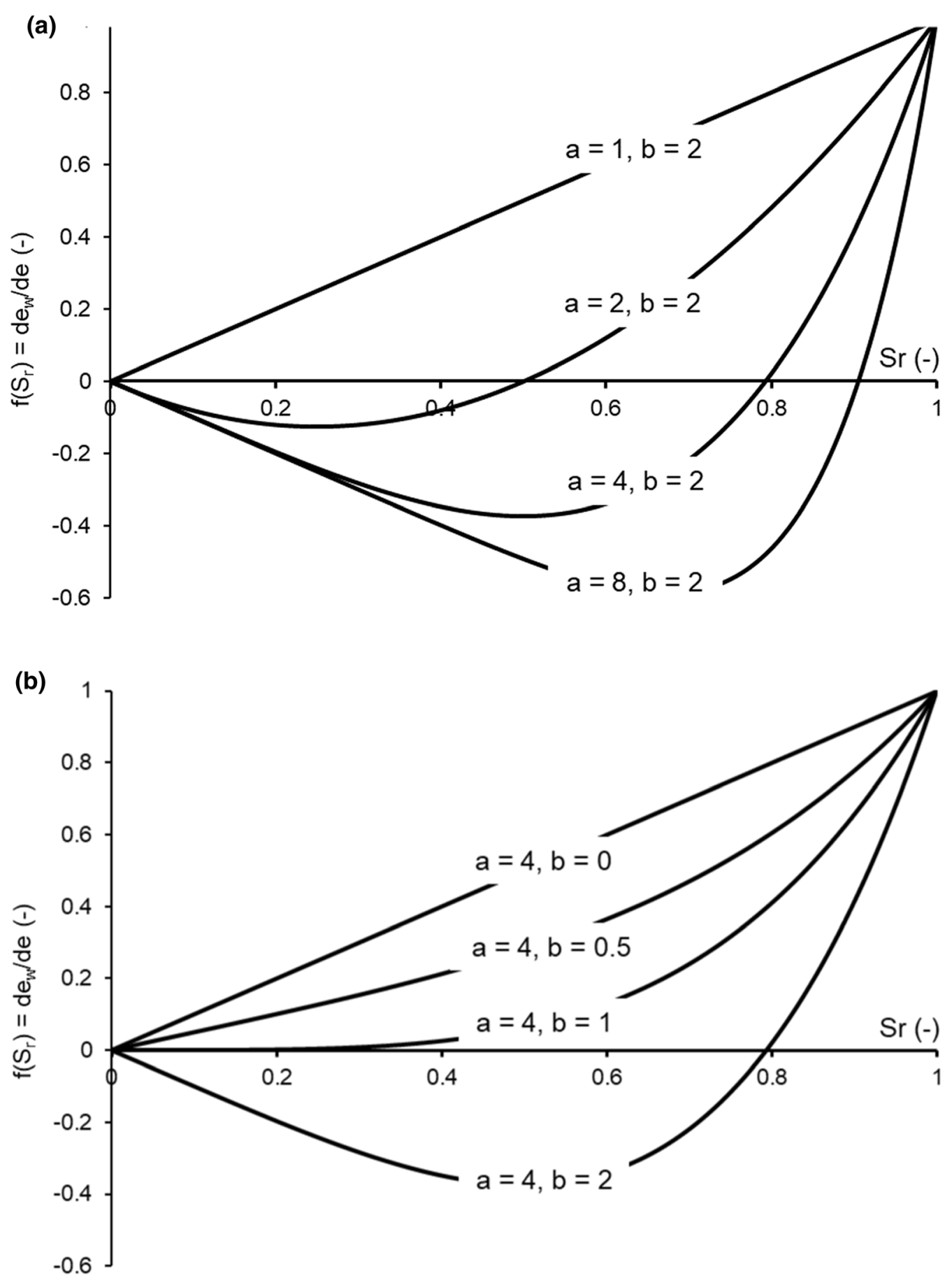

Fig. 3 Possible forms of coupling function assuming a variable saturation state of individual pores during volumetric deformation at constant suction: a effect of variation of parameter $\mathbf{a}$ and $\mathbf{b}$ effect of variation of parameter $\mathbf{b}$

resulting in a dry density of about $2000 \mathrm{~kg} / \mathrm{m}^{3}$ and a suction of $800 \mathrm{kPa}$ [33]. "Artificial" soils have been preferred in this work to natural ones because of their relatively controlled fabric, which facilitates the validation of modelling assumptions. This is, however, only a first step towards a more extensive validation of the proposed modelling methodology, which should next be assessed against the behaviour of more complex soils, including natural ones.

Calibration of each of the four retention models was performed against: (a) two isotropic loading tests at constant suctions of $100 \mathrm{kPa}$ and $200 \mathrm{kPa}$ (Fig. 4) in the case of Sivakumar [41], (b) three isotropic loading tests at constant suctions of $50 \mathrm{kPa}, 150 \mathrm{kPa}$ and $350 \mathrm{kPa}$ (Fig. 5) 

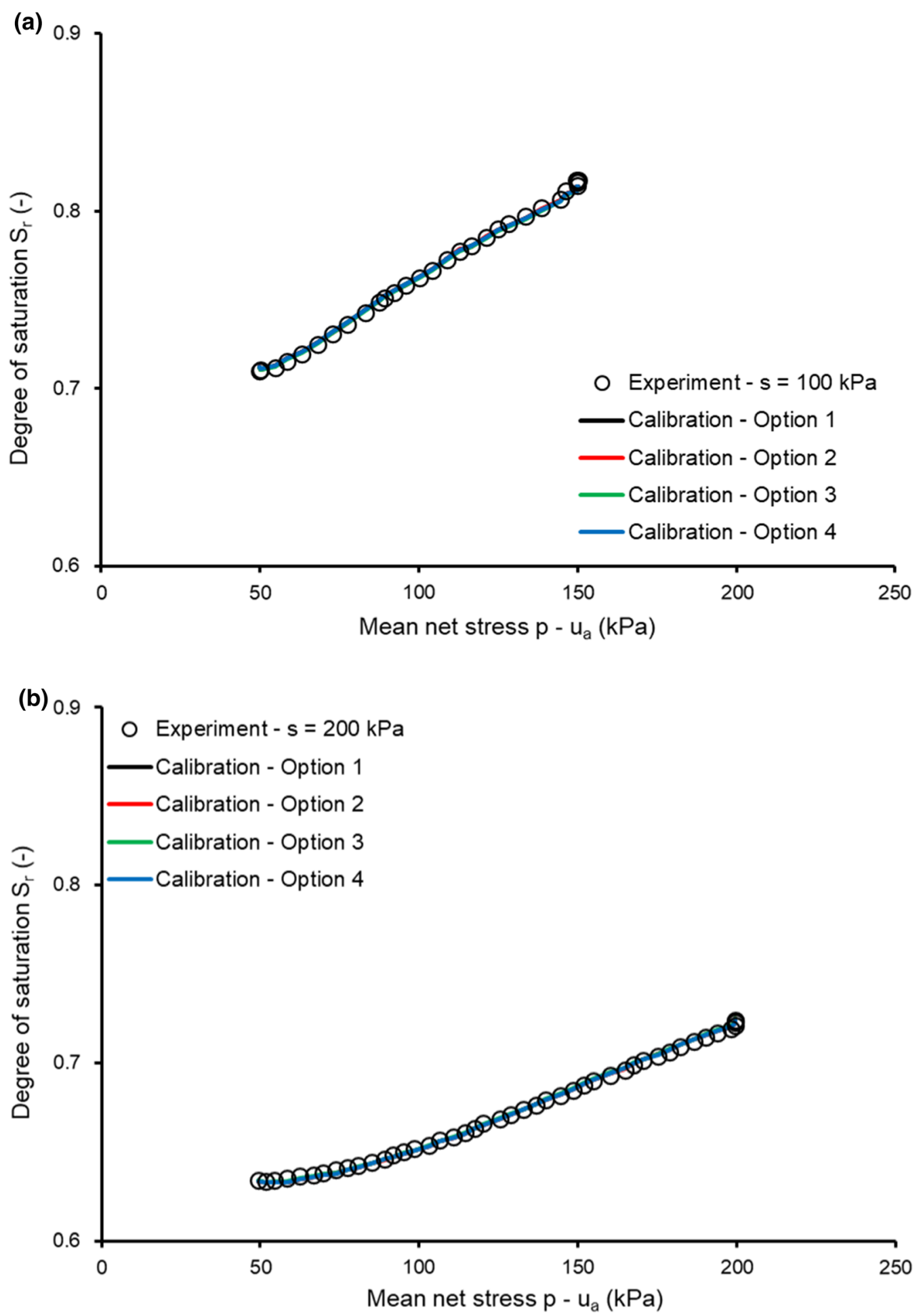

Fig. 4 Calibration of model parameters against isotropic loading tests at constant suction of a $100 \mathrm{kPa}$ and b $200 \mathrm{kPa}$ by Sivakumar [41]

in the case of Raveendiraraj [34], (c) three isotropic loading tests at constant suctions of $100 \mathrm{kPa}, 200 \mathrm{kPa}$ and $300 \mathrm{kPa}$ (Fig. 6) in the case of Sharma [39] and (d) two isotropic loading tests at constant suctions of $100 \mathrm{kPa}$ and $300 \mathrm{kPa}$ (Fig. 7) in the case of Rampino et al. [33]. In all cases, experimental data were interpolated according to the least square method where suction and void ratio were treated as independent variables, while the degree of saturation was the dependent variable. 

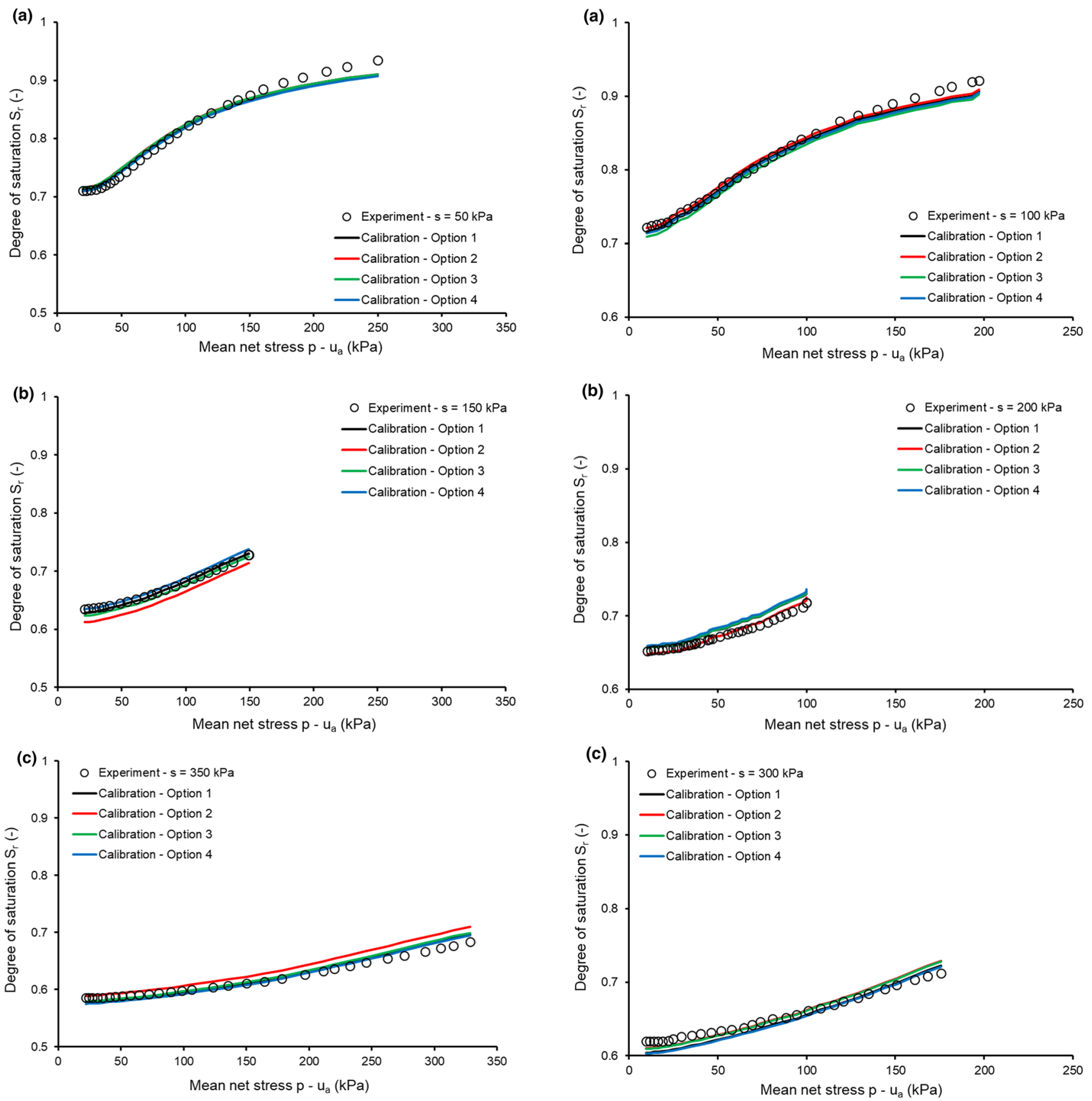

Fig. 5 Calibration of model parameters against isotropic loading tests at constant suction of a $50 \mathrm{kPa}$, b $150 \mathrm{kPa}$ and c $350 \mathrm{kPa}$ by Raveendiraraj [34]

During the interpolation of each test series, identical values of the parameters $a$ and $b$ were enforced in all four models. This is because these two parameters relate the increments of water ratio and void ratio at constant suction via the coupling function of Eq. (8), which is independent of the specific form of the function $C(s)$. The parameter values for each test series are summarised in Table 1 , where $a$ and $b$ are identical for all four models, while $c$ and $d$ vary with the chosen form of the function $C(s)$.

Fig. 6 Calibration of model parameters against isotropic loading tests at constant suction of a $100 \mathrm{kPa}, \mathbf{b} 200 \mathrm{kPa}$ and c $300 \mathrm{kPa}$ by Sharma [39]

Figures 4, 5, 6 and 7 indicate a good agreement between experimental and calibrated behaviour, thus confirming the ability of all models to predict the degree of saturation of different soils subjected to isotropic loading at constant suction.

Figure 8 plots the coupling functions of Eq. (8) generated by the parameters $a$ and $b$ corresponding to the different test series shown in Table 1. Figure 8 shows that the data by Sivakumar [41], Raveendiraraj [34] and Sharma 

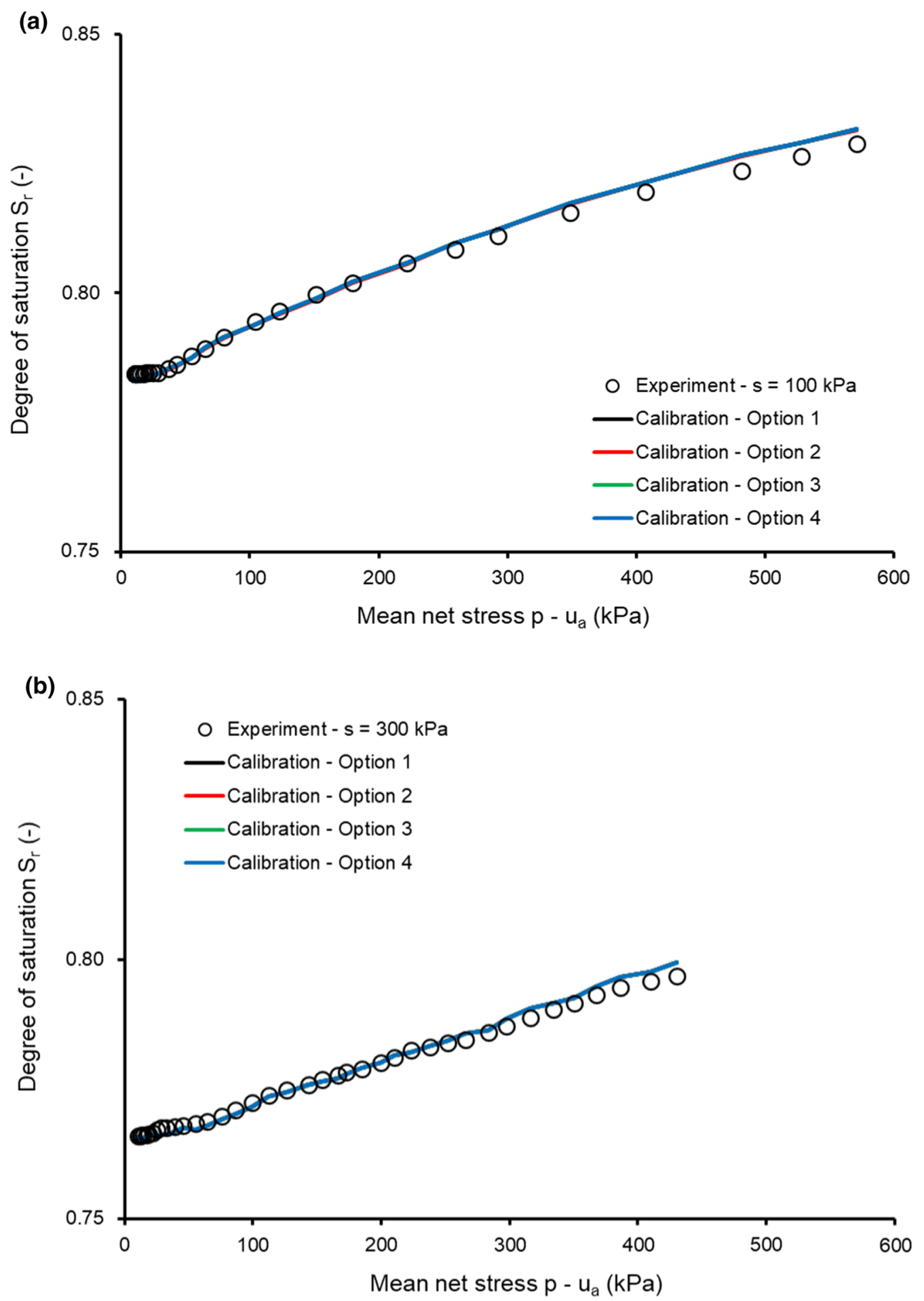

Fig. 7 Calibration of model parameters against isotropic loading tests at constant suction of a $100 \mathrm{kPa}$ and $\mathbf{b} 300 \mathrm{kPa}$ by Rampino et al. [33]

[39] produce similar coupling functions as they refer to similar soils, which are mostly made of Speswhite kaolin statically compacted to $400 \mathrm{kPa}$ at a dry of optimum water content of $25 \%$, resulting in a dry density of about $1190-1200 \mathrm{~kg} / \mathrm{m}^{3}$. The data by Rampino et al. [33] produce instead a different coupling function, which attains larger negative values as it refers to a coarser material, i.e. a silty sand compacted according to the modified Proctor method at the optimum water content of $9.8 \%$, resulting in a larger dry density of $2000 \mathrm{~kg} / \mathrm{m}^{3}$. This may suggest that coarser soils tend to exhibit a form of coupling function that attains larger negative values than finer soils, which is 
Table 1 Model parameters

\begin{tabular}{|c|c|c|c|c|c|c|c|c|c|c|}
\hline & \multirow[b]{3}{*}{ a } & \multirow[b]{3}{*}{$\mathrm{b}$} & \multicolumn{8}{|c|}{ Options for the expression of $C(s)$} \\
\hline & & & \multicolumn{2}{|c|}{ Option 1} & \multicolumn{2}{|c|}{ Option 2} & \multicolumn{2}{|c|}{ Option 3} & \multicolumn{2}{|c|}{ Option 4} \\
\hline & & & $\mathrm{c}$ & d & $\mathrm{c}$ & d & $\mathrm{c}$ & d & $\mathrm{c}$ & d \\
\hline Sivakumar [41] & 7.03 & 1.17 & 1.89 & 0.991 & 77.9 & 6.23 & 0.034 & 133 & 1.06 & 0.555 \\
\hline Raveendiraraj [34] & 5.98 & 1.24 & 2.44 & 0.775 & 878 & 5.22 & 0.497 & 14.4 & 1.20 & 0.415 \\
\hline Sharma [39] & 5.90 & 1.31 & 0.713 & 1.09 & 3.85 & 3.44 & 0.013 & 133 & 0.547 & 0.728 \\
\hline Rampino et al. [33] & 1.24 & 15.5 & 2.94 & 0.097 & 874 & 0.686 & 17,983 & 0.691 & 1.37 & 0.052 \\
\hline
\end{tabular}

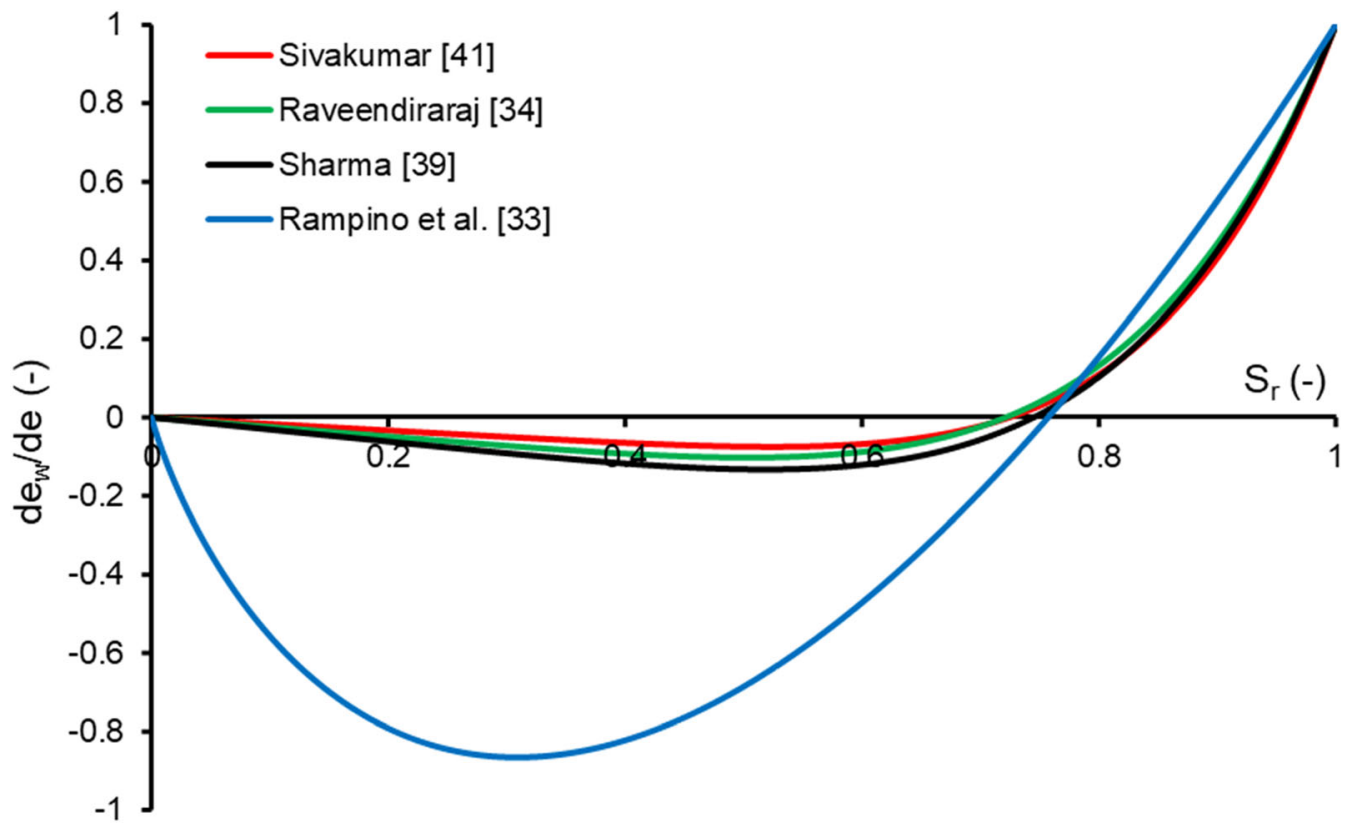

Fig. 8 Coupling functions of the materials tested by Sivakumar [41], Raveendiraraj [34], Sharma [39] and Rampino et al. [33]

also consistent with the experimental observation in the literature of an increase of water ratio during compression of moderately coarse soils at constant suction [6], i.e. a behaviour associated with negative values of the coupling function.

The data from Sivakumar [41], Raveendiraraj [34] and Sharma [39] cover water saturation levels greater than 0.58 , while the data from Rampino et al. [33] cover saturation levels greater than 0.75 . This means that the graphs of Fig. 8 constitute an extrapolation of the coupling function over the low saturation range.

It is interesting to highlight that a workable retention model could have been alternatively obtained by relating the suction-dependent integration constant $C(s)$ to the isochoric retention behaviour of the soil. An isochoric retention curve describes the variation of degree of saturation with suction when void ratio is constant, and thus, the relationship between the function $C(s)$ and the generic isochoric retention curve $S_{r}\left(e_{o}, s\right)$ (at constant void ratio $e_{o}$ ) is obtained by posing $e=e_{o}$ inside Eq. (11) as:

$C(s)=\left[1 / S_{r}\left(e_{o}, s\right)^{a-1}-1\right] / e_{o}^{b(a-1)}$

Substitution of Eq. (16) into Eq. (11) leads to the following alternative formulation of the retention model in terms of the isochoric retention curve $S_{r}\left(e_{o}, s\right)$ instead of the function $C(s)$ :

$$
\begin{gathered}
S_{r}(e, s)=\left\{1 /\left[1+\left(1 / S_{r}\left(e_{o}, s\right)^{a-1}-1\right)\right.\right. \\
\left.\left.\left(e / e_{o}\right)^{b(a-1)}\right]\right\}^{1 /(a-1)}
\end{gathered}
$$

Equation (17), therefore, accounts for the combined effects of suction variation (under isochoric conditions) and void ratio variation (under constant suction) on the change of degree of saturation. 
The separation of the effect of suction on retention behaviour (described by the isochoric curve) from that of volumetric deformation (described by the coupling function of Eq. (11) allows the adoption of a two-stage model calibration procedure. According to this procedure, the isochoric retention curve $S_{r}\left(e_{o}, s\right)$ is first defined by bestfitting experimental retention data at constant void ratio with a mathematical expression of choice. Next, this isochoric retention curve is substituted inside Eq. (17), which is then fitted to additional data from compression tests (or from retention tests corresponding to different values of void ratio) for selecting parameters $a$ and $b$.

According to Eq. (16), the following relationship must also exist between two isochoric curves at distinct values of void ratio $e_{o}$ and $e_{1}$ to preserve the uniqueness of the function $C(s)$ :

$$
\begin{aligned}
& {\left[1-S_{r}\left(e_{o}, s\right)^{a-1}\right] / S_{r}\left(e_{o}, s\right)^{a-1}} \\
& \quad=k\left[1-S_{r}\left(e_{1}, s\right)^{a-1}\right] / S_{r}\left(e_{1}, s\right)^{a-1}
\end{aligned}
$$

where $k$ is an "isochoric retention mapping factor" defined as:

$k=\left(e_{o} / e_{1}\right)^{b(a-1)}$

Equation (18) can, therefore, be regarded as the intrinsic signature of the retention behaviour of the soil under isochoric conditions [29, 32].

\section{Model validation}

Predictions from all four retention models with the parameters of Table 1 have also been compared against additional data not used during calibration. To better assess accuracy, the experimental values of void ratio have been introduced inside the models to calculate the degree of saturation, though a suitable mechanical law [5, 15] could have also been used to predict the values of void ratio.

Figure 9 compares the experimental and predicted values of degree of saturation during two isotropic compression tests by Sivakumar [41] at constant suctions of $200 \mathrm{kPa}$ (Fig. 9a) and $300 \mathrm{kPa}$ (Fig. 9b), respectively. For the test at a suction of $200 \mathrm{kPa}$ (Fig. 9a), the four modelling options generate virtually identical predictions of degree of saturation with a good match to the experimental data. Instead, for the test at a constant suction of $300 \mathrm{kPa}$ (Fig. 9b), the quality of the match is variable, with options 1 and 3 producing more accurate predictions compared to options 2 and 4 . Note that the suction of $300 \mathrm{kPa}$ is higher than the maximum level of $200 \mathrm{kPa}$ considered during calibration (Fig. 4). Therefore, when predictions are extrapolated beyond the suction calibration range, the accuracy of calculations appears to be dependent on the chosen modelling option.

Figure 10 compares the predicted and experimental behaviour of the soil during a wetting test conducted by Raveendiraraj [34] under a constant mean net stress of $100 \mathrm{kPa}$. This soil path differs from the constant-suction loading considered during calibration (Fig. 5), yet all four models predict the degree of saturation with good accuracy.

Figure 11 compares the experimental and predicted values of degree of saturation during an isotropic loadingunloading test performed by Sharma [39] at constant suction of $200 \mathrm{kPa}$. All models correctly predict the large saturation increase during loading (caused by the large reduction of void ratio) and the small saturation decrease during unloading (caused by the small increase of void ratio), thanks to the link between degree of saturation and void ratio in Eq. (11). Figure 11 also shows that modelling options 1, 3 and 4 accurately predict the measured values of degree of saturation, while modelling option 2 slightly underestimates the experimental data.

The ability of all models to reproduce the soil behaviour is further validated against two wetting tests conducted by Sharma [39] under constant mean net stresses of $10 \mathrm{kPa}$ (Fig. 12a) and 50 kPa (Fig. 12b), respectively. Like before, also in this case the models can accurately predict the variation of degree of saturation along a stress path that differs from the constant-suction loading considered during calibration. Figure 12 also shows, once again, that modelling options 1, 3 and 4 simulate the soil behaviour more accurately than option 2, which wrongly predicts the full saturation of the sample at the end of wetting under a constant mean net stress of $10 \mathrm{kPa}$ (Fig. 12a).

Finally, Fig. 13 compares the experimental and predicted behaviour of the coarser soil tested by Rampino et al. [33] during isotropic loading at a constant suction of $200 \mathrm{kPa}$. Inspection of Fig. 13 shows that all models generate virtually identical predictions of degree of saturation with an excellent match to measurements. Such a good match is partly expected as the suction of $200 \mathrm{kPa}$ falls right in the middle of the calibration range from 100 to $300 \mathrm{kPa}$ (Fig. 7).

By considering all data sets combined, model predictions have been validated against laboratory measurements covering suctions from 10 to $400 \mathrm{kPa}$ and saturation levels higher than 0.58 . This validation has also been performed against a variety of soil paths, including wetting/drying paths generated by loading/unloading at constant suction and wetting paths generated by a reduction of suction at constant mean net stress. No validation has, however, been performed against drying paths generated by an increase of suction. Future research should therefore aim to explore drying paths at higher suction levels and lower degrees of saturation than those considered in the present work. 

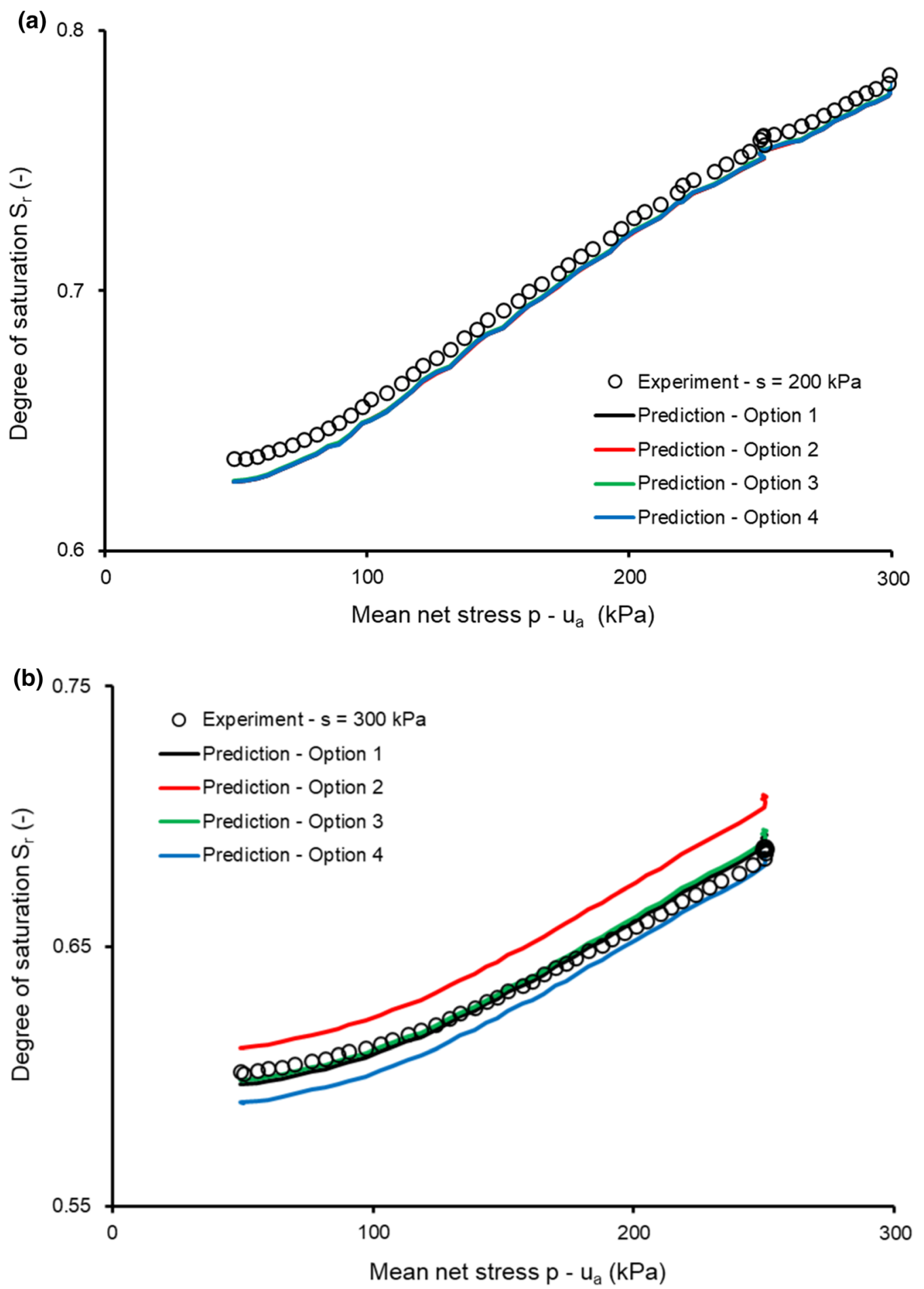

Fig. 9 Model validation against isotropic loading tests at constant suction of a $200 \mathrm{kPa}$ and b $300 \mathrm{kPa}$ by Sivakumar [41]

\section{Conclusions}

The paper has presented a methodology for formulating soil-water retention models in deformable soils. The approach originates from the examination of the microstructure of the soil, which is idealised as a granular medium incorporating larger empty pores (i.e. air-filled) and smaller saturated pores (i.e. water-flooded). Based on this idealisation, the paper has postulated the existence of a differential coupling function that relates the increments of water ratio and void ratio at constant suction through a proportionality factor depending on degree of saturation. 


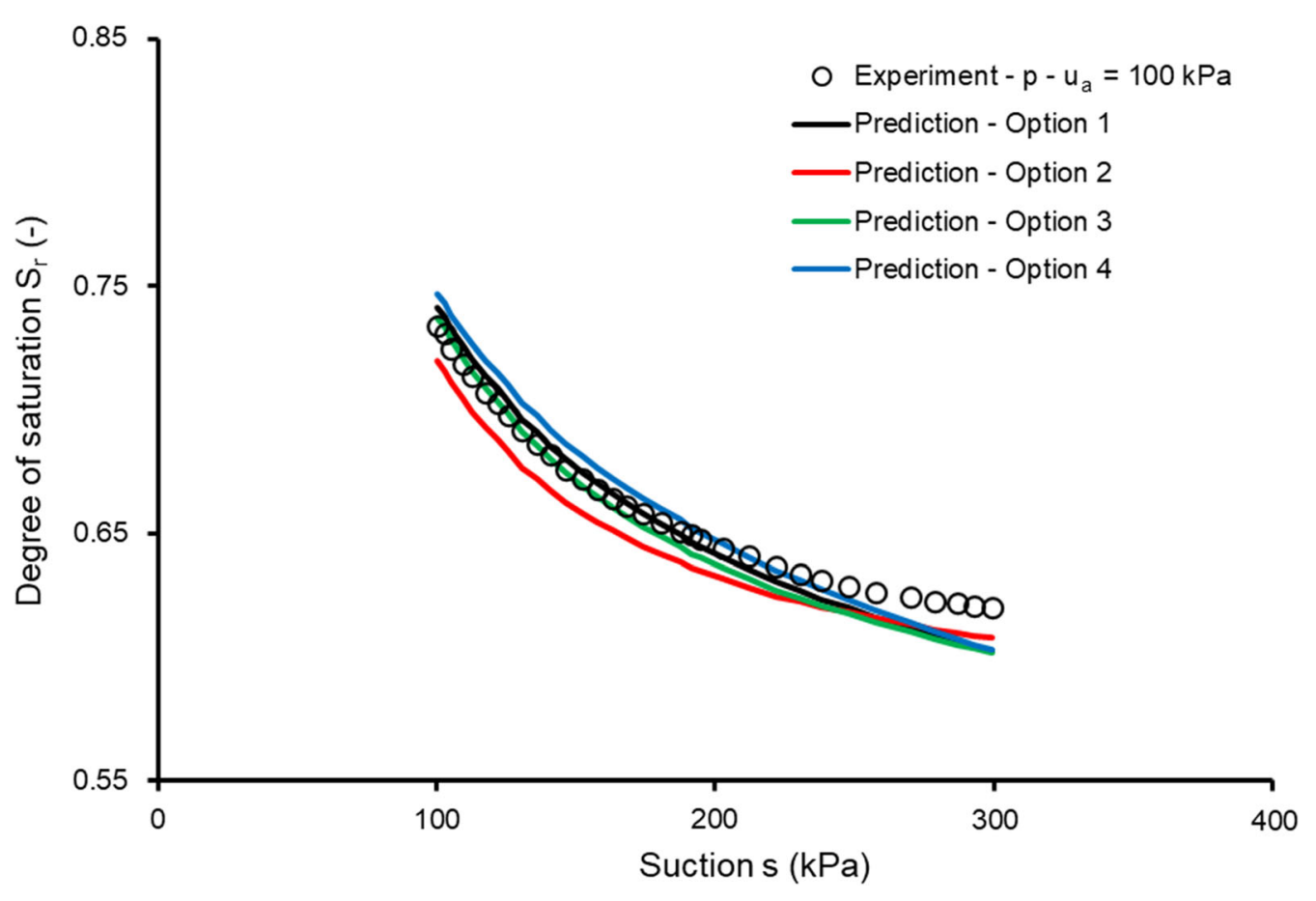

Fig. 10 Model validation against wetting tests at constant mean net stress of $100 \mathrm{kPa}$ by Raveendiraraj [34]

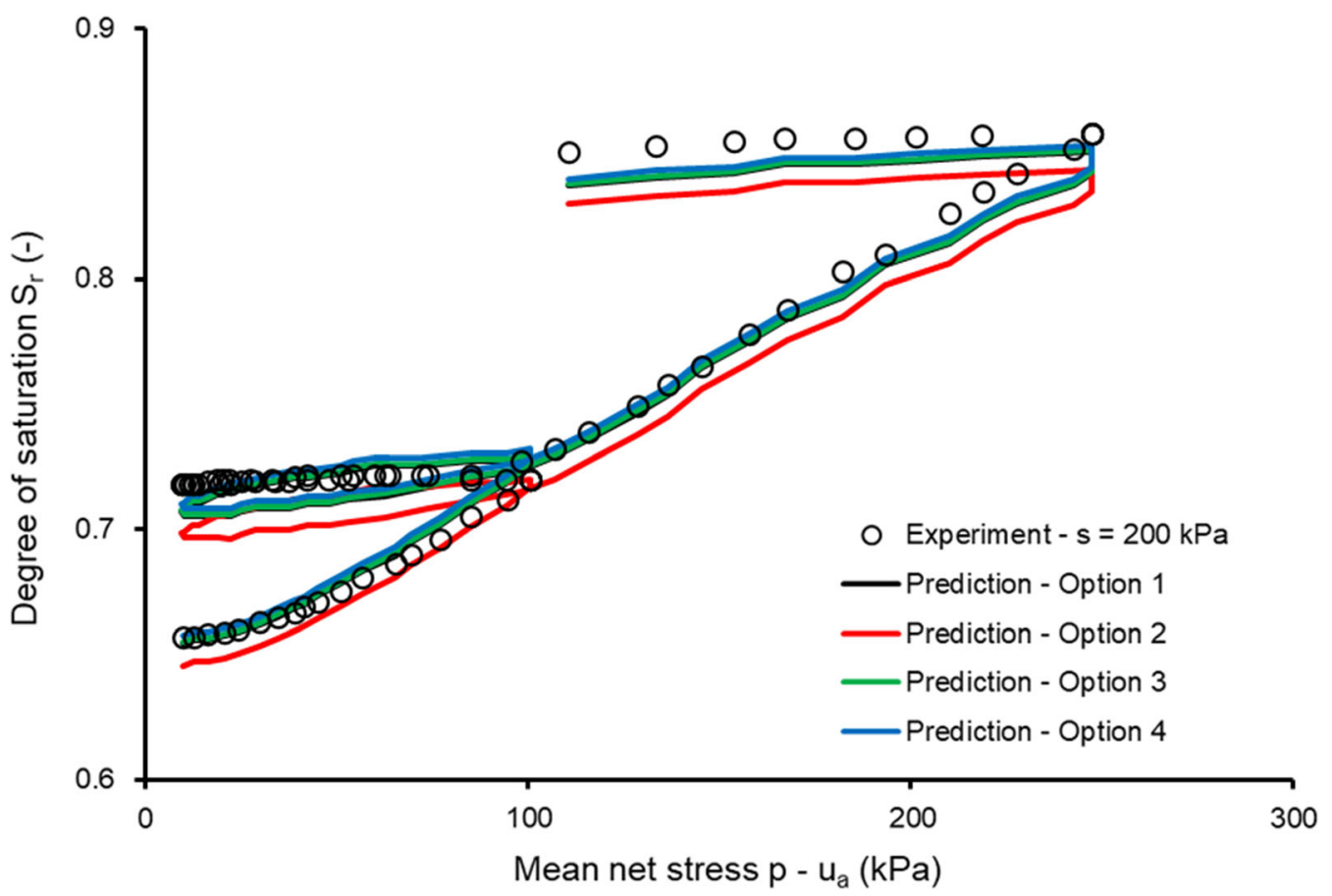

Fig. 11 Model validation against isotropic loading-unloading test at constant suction of $200 \mathrm{kPa}$ by Sharma [39]

Different mathematical forms of this differential coupling function have been proposed based on distinct interaction mechanisms between the increments of void ratio and water ratio at constant suction. Among these alternatives, the most general one has been integrated in a closed form resulting in a relationship between water ratio and void ratio with an integration constant that depends on the chosen level of suction. This suction-dependent integration constant can also be recast in terms of an isochoric retention curve, i.e. a retention curve at constant void ratio.

Four alternative analytical expressions of the suctiondependent integration constant have been considered, 

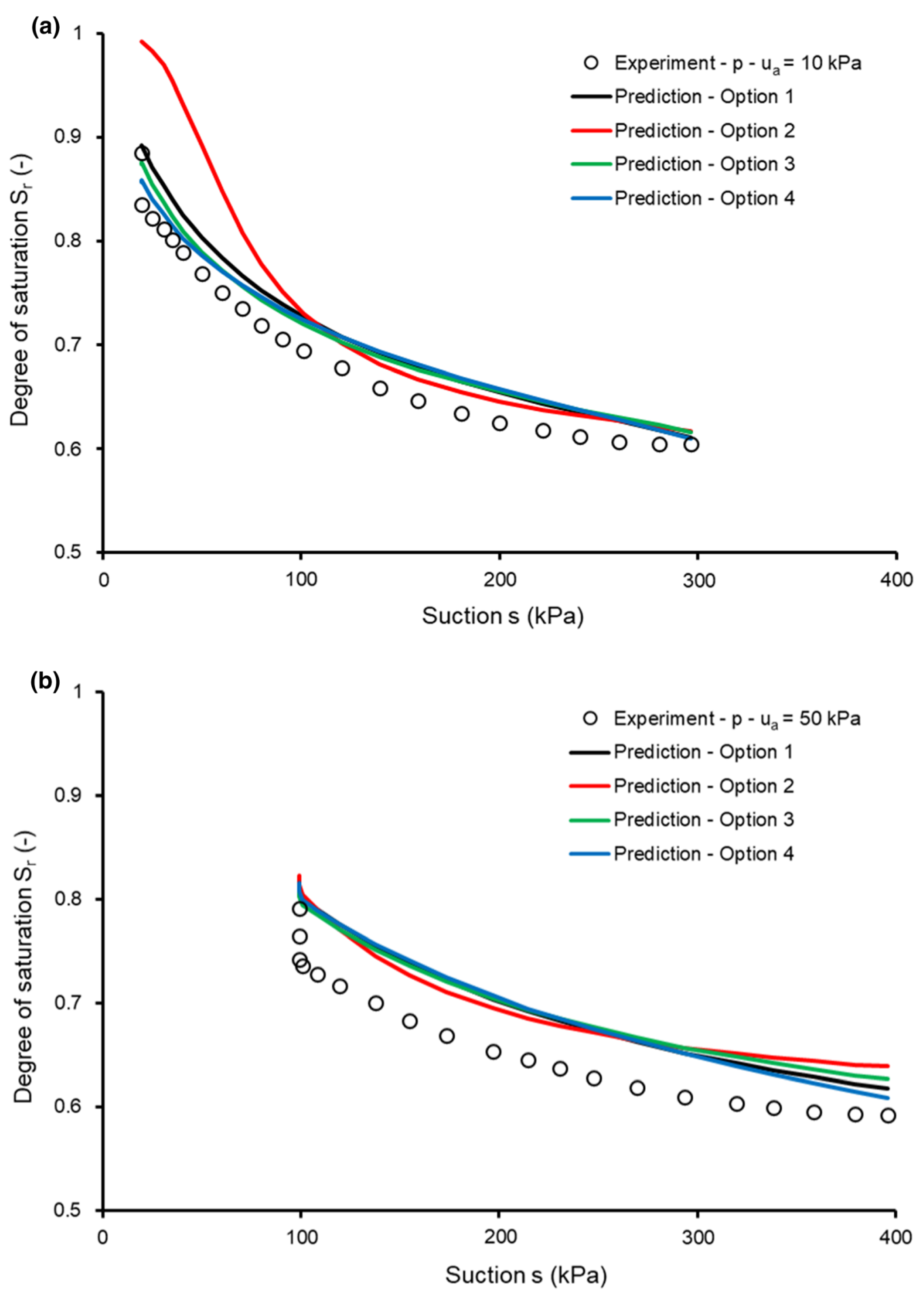

Fig. 12 Model validation against wetting tests at constant mean net stress of a $10 \mathrm{kPa}$ and $\mathbf{b} 50 \mathrm{kPa}$ by Sharma [39]

which has resulted in the formulation of four different models linking degree of saturation to void ratio and suction. Each model is formulated in terms of four parameters, i.e. two parameters inside the coupling function accounting for the effect of void ratio on retention behaviour and two parameters inside the chosen expression of the integration constant accounting for the effect of suction. This separation of the effects of void ratio and suction increases model flexibility and allows the formulation of equivalent retention laws with different mathematical forms. It also facilitates model calibration by associating different parameters to specific aspects of material behaviour.

The four retention models have been calibrated and validated against different sets of experimental data 


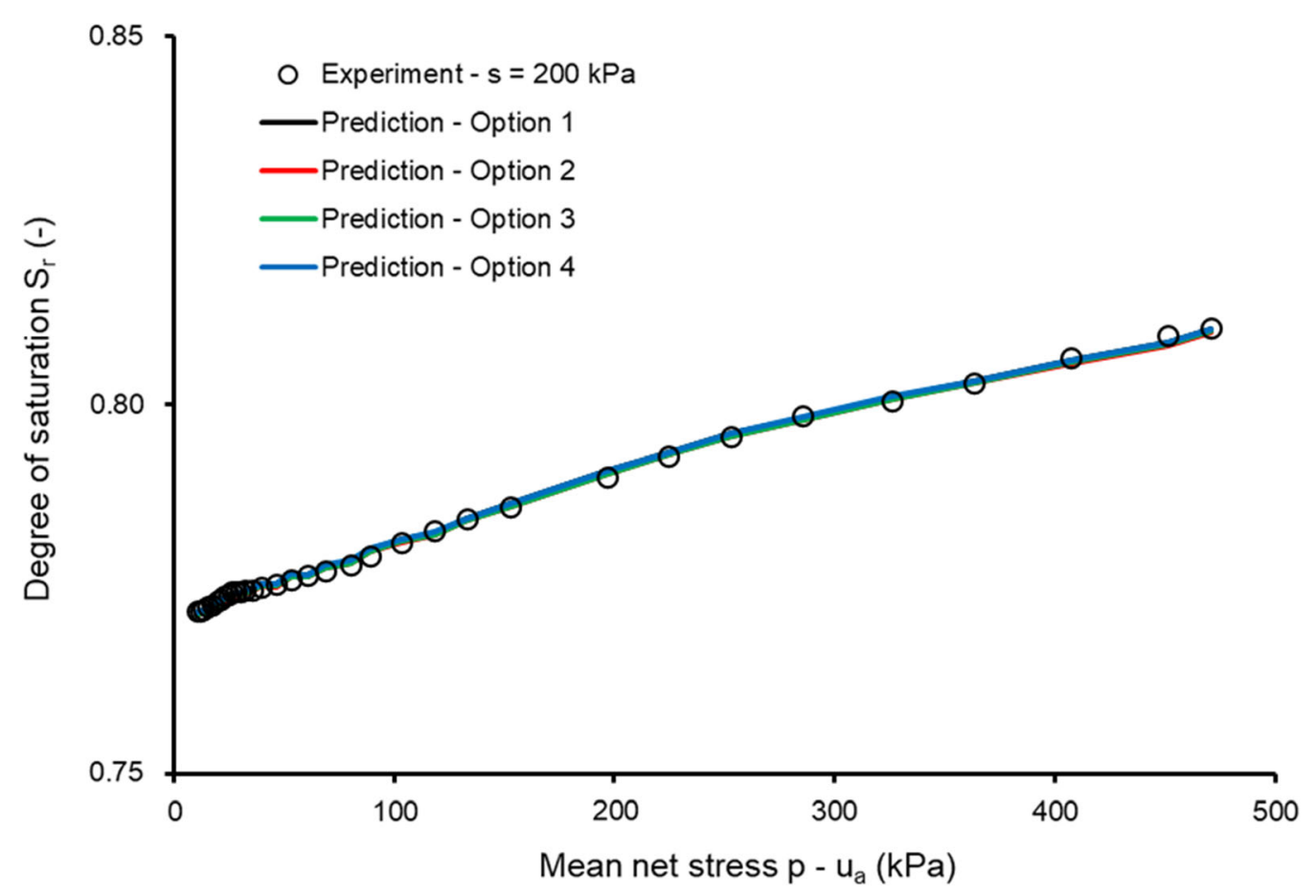

Fig. 13 Model validation against isotropic loading test at constant suction of $200 \mathrm{kPa}$ by Rampino et al. [33]

covering a broad range of soils, from relatively low activity clays to silty sands, that have been compacted at the optimum water content or dry of optimum, resulting in different dry densities. Comparison between calibrated and experimental data has generally confirmed that all four models can capture the retention behaviour of the different soils under variable levels of void ratio and suction. Validation against additional tests has also indicated that three out of four models can accurately extrapolate the soil behaviour to stress paths and suction levels not considered during calibration.

Past experimental evidence has shown that clays tend to exhibit a similar double-porosity fabric when compacted dry of optimum, regardless of their activity level, which would suggest that the proposed modelling approach may be generally relevant to compacted clays, including those of higher activity.

Finally, the proposed modelling framework could also be extended to account for hydraulic hysteresis and might be coupled with a mechanical law to generate a full hydromechanical model.

\section{Appendix}

To ensure that the coupling function of Eq. (8) is always equal or smaller than the corresponding value of the degree of saturation (i.e. to ensure that the graph of the coupling function stays always below the identity line in Fig. 3), the following inequality must be fulfilled:

$f_{c}\left(S_{r}\right)=b S_{r}^{a}+(1-b) S_{r} \leq S_{r}$

which can be rewritten as:

$b\left(S_{r}{ }^{a}-S_{r}\right) \leq 0$

Considering that $0 \leq S_{r} \leq 1$, Eq. (21) is satisfied when:

$1 \leq a$ and $0 \leq b$

Therefore, the two inequalities of Eq. (22) define the admissible range of values for parameters $a$ and $b$, which produces physically acceptable predictions of soil behaviour.

Let us now study the initial slope of the coupling function, i.e. the slope at $S_{r}=0$, which is particularly important because it tells whether the coupling function attains negative values over part of the saturation range. The slope of the coupling function is obtained by calculating the derivative of Eq. (8) as:

$d f_{c}\left(S_{r}\right) / d S_{r}=a b S_{r}{ }^{a-1}+1-b$

When $a=1$, this slope is constant and equal to one, which means that the coupling function coincides with the identity function regardless of the value of $b$. Instead, when $1<a$, the substitution of $S_{r}=0$ inside Eq. (23) yields the following expression:

$\mathrm{d} f_{c}\left(S_{r}=0\right) / \mathrm{d} S_{r}=1-b$ 
which indicates that the initial slope of the coupling function is positive when $0 \leq b<1$, it is zero when $b=1$ and it is negative when $b>1$, as shown in Fig. $3 \mathrm{~b}$.

Funding Open access funding provided by Università degli Studi di Genova within the CRUI-CARE Agreement.

Open Access This article is licensed under a Creative Commons Attribution 4.0 International License, which permits use, sharing, adaptation, distribution and reproduction in any medium or format, as long as you give appropriate credit to the original author(s) and the source, provide a link to the Creative Commons licence, and indicate if changes were made. The images or other third party material in this article are included in the article's Creative Commons licence, unless indicated otherwise in a credit line to the material. If material is not included in the article's Creative Commons licence and your intended use is not permitted by statutory regulation or exceeds the permitted use, you will need to obtain permission directly from the copyright holder. To view a copy of this licence, visit http://creativecommons. org/licenses/by/4.0/.

\section{References}

1. ASTM (1991) D1557: Test method for laboratory compaction characteristics of soils using modified effort $56000 \mathrm{ft} \cdot \mathrm{lbf} / \mathrm{ft} 3$ $\left(2700 \mathrm{kNm} / \mathrm{m}^{3}\right)$. In: 1991 annual book of ASTM standards. ASTM, Philadelphia, pp 228-235

2. Azizi A, Jommi C, Musso G (2017) A water retention model accounting for the hysteresis induced by hydraulic and mechanical wetting-drying cycles. Comput Geotech 87:86-98

3. Beckett CT, Augarde CE (2013) Prediction of soil water retention properties using pore-size distribution and porosity. Can Geotech J 50(4):435-450

4. Brooks R, Corey T (1964) Hydraulic properties of porous media. In: Hydrology Papers. Colorado State University, Fort Collins

5. Bruno AW, Gallipoli D (2019) A coupled hydromechanical bounding surface model predicting the hysteretic behaviour of unsaturated soils. Comput Geotech 110:287-295

6. Buenfil C, Romero E, Lloret A, Gens A (2005) Hydro-mechanical behaviour of a clayey silt under isotropic compression. In: Schanz T. (eds) Unsaturated Soils: Experimental Studies. Springer Proceedings in Physics, vol 93. Springer, Berlin

7. Casini F, Vaunat J, Romero E, Desideri A (2012) Consequences on water retention properties of double-porosity features in a compacted silt. Acta Geotech 7(2):139-150

8. Cuisinier O, Laloui L (2004) Fabric evolution during hydromechanical loading of a compacted silt. Int J Numer Anal Meth Geomech 28(6):483-499

9. Della Vecchia G (2009) Coupled hydro-mechanical behaviour of compacted clayey soils. In: Ph.D. thesis, Politecnico di Milano

10. Della Vecchia G, Dieudonné AC, Jommi C, Charlier R (2015) Accounting for evolving pore size distribution in water retention models for compacted clays. Int J Numer Anal Meth Geomech 39(7):702-723

11. Dieudonne AC, Della Vecchia G, Charlier R (2017) Water retention model for compacted bentonites. Can Geotech J 54(7):915-925

12. Fredlund DG, Xing A (1994) Equations for the soil-water characteristic curve. Can Geotech J 31(4):521-532
13. Frydman S, Baker R (2009) Theoretical soil-water characteristic curves based on adsorption, cavitation, and a double porosity model. Int J Geomech 9(6):250-257

14. Gallipoli D (2012) A hysteretic soil-water retention model accounting for cyclic variations of suction and void ratio. Géotechnique 62(7):605-616

15. Gallipoli D, Bruno AW (2017) A bounding surface compression model with a unified virgin line for saturated and unsaturated soils. Géotechnique 67(8):703-712

16. Gallipoli D, Bruno AW, D’Onza F, Mancuso C (2015) A bounding surface hysteretic water retention model for deformable soils. Géotechnique 65(10):793-804

17. Gallipoli D, Gens A, Sharma R, Vaunat J (2003) An elasto-plastic model for unsaturated soil incorporating the effects of suction and degree of saturation on mechanical behaviour. Géotechnique 53(1):123-135

18. Gallipoli D, Wheeler SJ, Karstunen M (2003) Modelling the variation of degree of saturation in a deformable unsaturated soil. Géotechnique 53(1):105-112

19. Gens A, Valleján B, Sánchez M, Imbert C, Villar MV, Van Geet M (2011) Hydromechanical behaviour of a heterogeneous compacted soil: Experimental observations and modelling. Géotechnique 61(5):367-386

20. Hu R, Chen YF, Liu HH, Zhou CB (2013) A water retention curve and unsaturated hydraulic conductivity model for deformable soils: consideration of the change in pore-size distribution. Géotechnique 63(16):1389-1405

21. Iyer KKR, Joseph J, Lopes BCFL, Singh DN, Tarantino A (2018) Water retention characteristics of swelling clays in different compaction states. Geomech Geoeng 13(2):88-103

22. Iyer KKR, Shetty R, Joseph J, Singh DN (2019) Influence of microstructure on drying- and wetting-characteristics of finegrained soils. Geomech Geoeng 14(4):271-284

23. Koliji A, Laloui L, Cusinier O, Vulliet L (2006) Suction induced effects on the fabric of a structured soil. Transp Porous Media 64(2):261

24. Mašín D (2010) Predicting the dependency of a degree of saturation on void ratio and suction using effective stress principle for unsaturated soils. Int J Numer Anal Meth Geomech 34(1):73-90

25. Monroy R, Zdravkovic L, Ridley A (2010) Evolution of microstructure in compacted London Clay during wetting and loading. Géotechnique 60(2):105-119

26. Morvan M, Wong H, Branque D (2011) Incorporating porositydependent hysteretic water retention behavior into a new constitutive model of unsaturated soils. Can Geotech J 48(12):1855-1869

27. Navarro V, Asensio L, De la Morena G, Pintado X, Yustres Á (2015) Differentiated intra- and inter-aggregate water content models of mx-80 bentonite. Appl Clay Sci 118:325-336

28. Ng CWW, Sadeghi H, Hossen SKB, Chiu CF, Alonso EE, Baghbanrezvan S (2016) Water retention and volumetric characteristics of intact and recompacted loess. Can Geotech J 53(8):1258-1269

29. Nuth M, Laloui L (2008) Advances in modelling hysteretic water retention curve in deformable soils. Comput Geotech 35(6):835-844

30. Otalvaro IF, Neto MPC, Delage P, Caicedo B (2016) Relationship between soil structure and water retention properties in a residual compacted soil. Eng Geol 205:73-80

31. Pasha AY, Khoshghalb A, Khalili N (2016) Pitfalls in interpretation of gravimetric water content-based soil-water characteristic curve for deformable porous media. Int $\mathrm{J}$ Geomech 16(6):D4015004

32. Pasha AY, Khoshghalb A, Khalili N (2020) Evolution of isochoric water retention curve with void ratio. Comput Geotech 122:103536 
33. Rampino C, Mancuso C, Vinale F (2000) Experimental behaviour and modelling of an unsaturated compacted soil. Can Geotech $\mathrm{J}$ 37(4):748-763

34. Raveendiraraj A (2009) Coupling of mechanical behaviour and water retention behaviour in unsaturated soils. In: Ph.D. thesis, University of Glasgow.

35. Romero E, Della Vecchia G, Jommi C (2011) An insight into the water retention properties of compacted clayey soils. Géotechnique 61(4):313-328

36. Romero E, Gens A, Lloret A (1999) Water permeability, water retention and microstructure of unsaturated compacted Boom clay. Eng Geol 54(1-2):117-127

37. Romero E, Jommi C (2008) An insight into the role of hydraulic history on the volume changes of anisotropic clayey soils. Water Resour Res 44(5):W12412

38. Romero E, Vaunat J (2000) Retention curves of deformable clays. In: Experimental evidence and theoretical approaches in unsaturated soils. CRC Press, pp 99-114.

39. Sharma RS (1998) Mechanical behaviour of unsaturated highly expansive clays. In: Ph.D. thesis, University of Oxford.

40. Simms PH, Yanful EK (2002) Predicting soil-water characteristic curves of compacted plastic soils from measured pore-size distributions. Géotechnique 52(4):269-278

41. Sivakumar V (1993) A critical state framework for unsaturated soil. In: Ph.D. thesis, University of Sheffield.

42. Sun DA, Cui HB, Matsuoka H, Sheng DC (2007) A three-dimensional elastoplastic model for unsaturated compacted soils with hydraulic hysteresis. Soils Found 47(2):253-264
43. Sun DA, Sheng D, Sloan SW (2007) Elastoplastic modelling of hydraulic and stress-strain behaviour of unsaturated soils. Mech Mater 39(3):212-221

44. Tarantino A (2009) A water retention model for deformable soils. Géotechnique 59(9):751-762

45. Tsiampousi A, Zdravković L, Potts DM (2013) A three-dimensional hysteretic soil-water retention curve. Géotechnique 63(2): $155-164$

46. Van Genuchten MT (1980) A closed-form equation for predicting the hydraulic conductivity of unsaturated soils. Soil Sci Soc Am J 44(5):892-898

47. Vanapalli SK, Fredlund DG, Pufahl DE (1999) The influence of soil structure and stress history on the soil-water characteristics of a compacted till. Géotechnique 49(2):143-159

48. Wang Q, Tang AM, Cui YJ, Delage P, Gatmiri B (2012) Experimental study on the swelling behaviour of bentonite/claystone mixture. Eng Geol 124:59-66

49. Wheeler SJ, Karube D (1995) State of the art report—constitutive modelling. Proc Int Conf Unsaturat Soils Paris 3:1323-1356

50. Zhou AN, Sheng D, Carter JP (2012) Modelling the effect of initial density on soil-water characteristic curves. Géotechnique 62(8):669-680

Publisher's Note Springer Nature remains neutral with regard to jurisdictional claims in published maps and institutional affiliations. 